Article

\title{
Studying the Effectiveness of Polyacrylamide (PAM) Application in Hydrocarbon Reservoirs at Different Operational Conditions
}

\author{
Kingsley Godwin Uranta, Sina Rezaei-Gomari * (1), Paul Russell and Faik Hamad \\ School of Science, Engineering and Design, Teesside University, Middlesbrough TS1 3BA, UK; \\ K.Uranta@tees.ac.uk (K.G.U.); P.Russell@tees.ac.uk (P.R.); F.Hamad@tees.ac.uk (F.H.) \\ * Correspondence: s.rezaei-gomari@tees.ac.uk
}

Received: 25 July 2018; Accepted: 18 August 2018; Published: 22 August 2018

\begin{abstract}
The water-soluble polymer PAM (polyacrylamide) is used in enhanced oil recovery (EOR) operations. It is pumped into water injection wells to increase the viscosity of the injected water and in turn to direct more oil towards production wells. This EOR process is proven to be sensitive to operational well conditions such as hydrocarbon reservoir temperature, as well as the salinity of the injected water and/or formation water. These operational conditions lead to technical challenges ranging from the solubility of PAM in injection water to the behaviour of PAM inside the reservoir. To gain a clear picture of the functionality of PAM in EOR applications, this report characterizes its behaviour of in terms of degree of hydrolysis and changes in solution viscosity determined using Perkin Elmer spectrum 100 Fourier transform infrared-Attenuated total reflection (FTIR)-ATR and nuclear magnetic resonance spectroscopy $\left({ }^{1} \mathrm{H}\right.$ NMR) and a Fann model 35 Couette and Cole Parmer rotational viscometer, respectively. Different shear rates were investigated to determine the effect of shear on PAM gel stability. Experiments were performed for PAM mixed with formation brine at 50, 70 , and $90{ }^{\circ} \mathrm{C}$ for ageing times of up to 30 days. The results indicate that the degree of hydrolysis achieved after 30 days is much higher in saline solutions than in pure water, and that this effect is more pronounced at higher temperatures. For example, after 30 days at $50{ }^{\circ} \mathrm{C}$, the hydrolysis level was observed to be $53 \%$, rising to $65 \%$ at $70{ }^{\circ} \mathrm{C}$ and $75 \%$ at $90{ }^{\circ} \mathrm{C}$ in PAM mixed with brines. Similar trends were observed with viscosity, where lower viscosity was observed for samples at higher temperatures and salinities. It is thus reasonable to conclude that the degree of hydrolysis causes changes in the viscosity of the polymer gel, leading to a decline in its performance as it ages.
\end{abstract}

Keywords: polyacrylamide (PAM); polymer flooding; polymer gelation; operational conditions; rheology; hydrolysis; polymer ageing

\section{Introduction}

In oilfield reservoirs, EOR is designed to reduce the remaining residual oil after water or gas flooding to a minimum value. Conventional methods of oil production yield about one-third of the oil initially in place in a given reservoir and the remaining oil, representing almost two-thirds of the oil in place, is an attractive target for the application of EOR methods [1].

Chemical enhanced oil recovery (CEOR) is one of the main techniques of EOR and includes polymer, surfactant, or alkaline flooding. Several examples of CEOR techniques using nanofluids or liquid suspensions of nanoparticles dispersed in distilled water or brine have recently been investigated by Nwidee et al. [2]. They showed that changes in the properties of nanoparticles depend on the nature of the materials used and the mechanisms applied. The injection of nanoparticle suspensions into porous media can lead to different adsorption, desorption, transport, and blocking behavior [3,4]. 
They can intervene in fluid mobility improvement, hence enhancing reservoir fluid displacement. Among the chemical techniques that can be employed, polymer flooding applications are most commonly used for the control of fluid mobility in oilfield reservoirs [3,5-8]. In an example of its use in China, over ten million tons of oil per year has been produced [1,9-11]. Two of the most frequently applied synthetic water-soluble polymers are PAM and hydrolyzed PAM (HPAM). PAM itself is considered to be the most widely deployed technique because of its low cost and risk [12].

In polymer flooding operations, an optimal viscosity of the displacing fluid (water) is required to ensure favourable mobility, leading to better oil recovery with good polymer injectivity at a lower cost. When a PAM solution is pumped into a reservoir from an injection well, the flow velocity, which is related to shear rate, will change from the well-bore to a few hundred feet away from the bore; consequently, the viscosity of the polymer solution will change [13]. This change in the rheological properties of the polymer solution can be influenced by temperature and salinity as the polymer ages.

Degradation of the polymer occurs when the amide groups present in the PAM structure are hydrolyzed in aqueous solution. Several reports have shown that the instability of PAM as it ages occurs mostly in the presence of elevated temperature and divalent salts [14,15]. Glover [16] explained that the most common dissolved salt in reservoirs is $\mathrm{NaCl}$, but many other salts such as $\mathrm{MgCl}_{2}$ and $\mathrm{CaCl}_{2}$ may be present in smaller quantities. Furthermore, Mungan [7] claimed that mixtures of monovalent $(\mathrm{NaCl})$ and divalent cations cause significant reductions in PAM viscosity. Such considerations have led to the recommendation of $70-82^{\circ} \mathrm{C}$ as a safe temperature range for the use of polyacrylamide in seawater and brine during polymer flooding [15-21]. Recently, Uranta et al. [22] conducted a correlation analysis to determine the safe maximum temperature point (SMTP) for polyacrylamide (PAM) in saline solutions, and it was concluded that the temperature range between $70-82^{\circ} \mathrm{C}$ is not adequate for the system given that the SMTP for PAM changes with type of salt and its concentration in the reservoir.

According to Uranta et al. [22] and as shown in Figure 1, the amide group in the structure of PAM consists of a carbonyl group bonded to one nitrogen and two hydrogen atoms $\left(\mathrm{CONH}_{2}\right)$, and the carbonyl functional group is composed of a carbon atom double-bonded to an oxygen atom $(C=O)$. The amide group changes to carboxylic $(\mathrm{RCOOH})$ through chemical transformation when dissolved in water at an elevated temperature. Additionally, this leads the amide group attached to the carbon in the PAM structure to be thermally hydrolyzed into negatively charged carboxylate $\left(\mathrm{COO}^{-}\right)$groups. In brine solutions, the PAM is now open to ionic functionality due to the presence of monovalent $(\mathrm{NaCl})$ or multivalent $\left(\mathrm{MgCl}_{2}\right.$ or $\mathrm{CaCl}_{2}$, etc.) compounds, giving rise to accelerated hydrolysis, which eventually results in a reduction in the viscosity of the PAM solution.

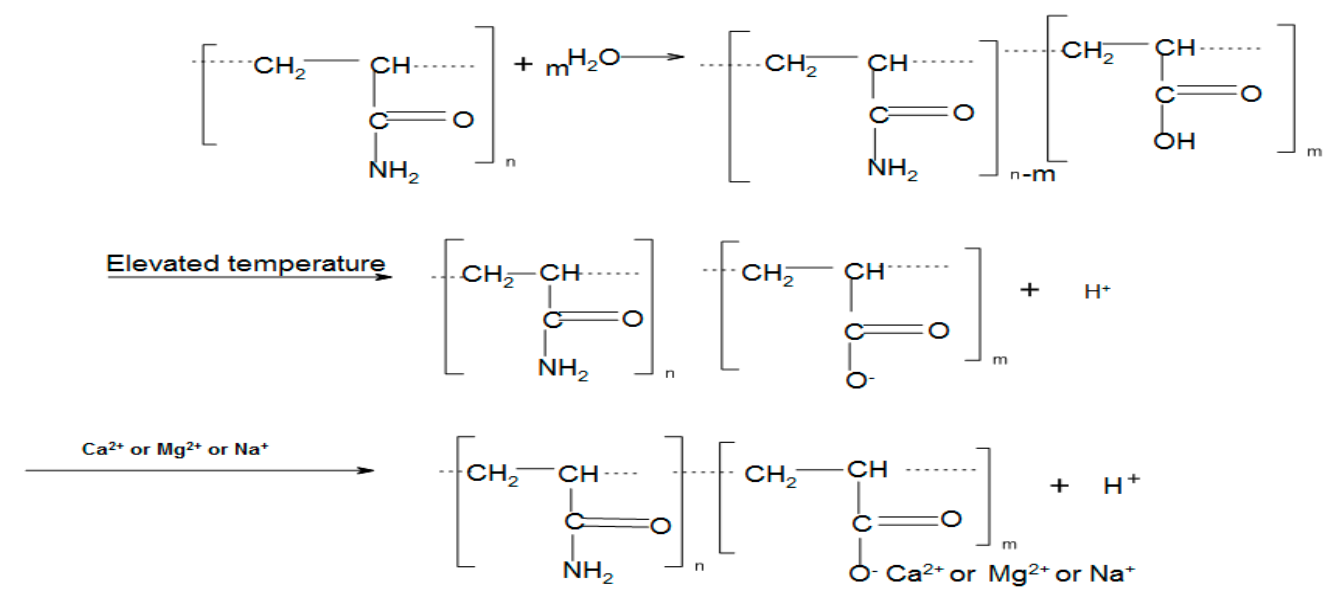

Figure 1. Chemistry of the hydrolysis of polyacrylamide (PAM) [22].

It is therefore important to evaluate and understand the behaviour of polymer solutions in different operational conditions to ensure that the polymer is not degraded as it moves through the 
reservoir. This study deals specifically with reservoir salinity and temperature, but other reservoir characteristics such as pressure could also impact polymer behaviour [4]. A study by Knight [23] confirmed that the mobility behaviour of polyacrylamide (PAM) when injected into the reservoir and its mobility control characteristics can best be determined in the laboratory by measuring the solution viscosity, which is then used to anticipate the behaviour of polyacrylamide flowing in the porous media of oilfield reservoirs. Thus, a laboratory study has been carried out of the rheological (viscosity) and hydrolytic changes experienced by PAM solutions at temperatures of 50,70 , and $90^{\circ} \mathrm{C}$ for different degrees of salinity, where the Fann viscometer system utilized a concentric cylinder with rotor and bob radii of 1.8415 and $1.725 \mathrm{~cm}$, respectively, as well as a Cole Parmer rotational viscometer with an $\mathrm{R}_{2}$ stainless steel spindle. The experimental results have been used to elucidate the time-dependent effects on the thermal stability of the thixotropic and pseudo-plastic behaviour of the PAM gel.

\section{Materials and Methods}

\subsection{Polymer Solution Preparation}

In this study, a high molecular weight (5-6 $\times 10^{6}$ Dalton) non-ionic water-soluble polymer of polyacrylamide (PAM) was selected and sourced from Sigma-Aldrich (St. Louis, MO, USA). Two types of polymer solution were prepared as follows: type 1 using deionized water; and type 2 synthesized formation water (hereafter called brine) mimicking the Draugen reservoir, North Sea, with total dissolved salts of 43,280 ppm. The reservoir is of sandstone formation [16], and Table 1 presents the composition of the synthesized brine. Polymer solutions with or without brine were prepared using a $1 \%(w / v)$ polymer $(10 \mathrm{~g})$ concentration in a $1000 \mathrm{~mL}$ beaker mixed with an electric stirrer. To prevent polymer degradation due to the presence of oxygen, $1 \%(w / v)$ or $10 \mathrm{~g}$ of sodium thiosulphate $\left(\mathrm{Na}_{2} \mathrm{~S}_{2} \mathrm{O}_{3}\right.$, concentration was added to $1000 \mathrm{~mL}$ of the solution as an oxygen scavenger.

Table 1. Reservoir saline composition [16].

\begin{tabular}{ccc}
\hline Components & Concentration (g) & Concentration (ppm) \\
\hline $\mathrm{NaCl}$ & 34,700 & 34,700 \\
$\mathrm{CaCl}_{2} \cdot 6 \mathrm{H}_{2} \mathrm{O}$ & 4900 & 4900 \\
$\mathrm{MgCl}_{2} \cdot 6 \mathrm{H}_{2} \mathrm{O}$ & 2700 & 2700 \\
$\mathrm{KCl}$ & 0.4 & 400 \\
$\mathrm{NaHCO}_{3}$ & 0.4 & 400 \\
$\mathrm{SrCl}_{2} \cdot 6 \mathrm{H}_{2} \mathrm{O}$ & 0.12 & 120 \\
$\mathrm{BaCl}_{2} \cdot 6 \mathrm{H}_{2} \mathrm{O}$ & 0.06 & 60 \\
Total dissolved salts (TDS) & $\mathbf{4 3 , 2 8 0}$ & $\mathbf{4 3 , 2 8 0}$ \\
\hline
\end{tabular}

\subsection{Ageing and Viscosity Measurement of PAM}

Two different viscometers, a Fann model 35 Couette and a Cole Parmer rotational viscometer, were utilized to measure solution viscosity. The prepared PAM solutions were aged in an oven at temperatures of 50,70 , and $90^{\circ} \mathrm{C}$ for time intervals of $0,1,2,4,10,20$, and 30 days, where an ageing time of zero refers to any measurements immediately after preparation. To assess the effect of shear rate on PAM stability, viscosity was measured at rotational speeds of 3, 6, 10, 30, 100, 200, 300, and $600 \mathrm{rpm}$ corresponding to shear rates of 5, 10, 17, 51, 170, 340,510, and $1021 \mathrm{~s}^{-1}$, respectively. The final result presented for the viscosity of each solution at different conditions is the average of three measurements and the error calculated based on test repeatability.

\subsection{Measurement of Extent of Hydrolysis of PAM}

The degree of hydrolysis gives a measure of the degradation of the polymer gel. The degree of hydrolysis is defined as the actual number of carboxylate $\left(\mathrm{COO}^{-}\right)$groups that could replace the amide group $\left(\mathrm{CONH}_{2}\right)$ divided by the total number of amide and carboxylate groups [24,25]. A two-stage 
process was used to determine the degree of hydrolysis achieved in the aged polymer samples. In stage 1, the polymer samples collected at time zero were analysed using nuclear magnetic resonance spectroscopy $\left({ }^{1} \mathrm{H}\right.$ NMR $)$ to set the initial degree of hydrolysis. Then, $20 \mathrm{mg}$ of the PAM solution was dissolved in $1 \mathrm{~mL}$ of deuterium oxide $\left(\mathrm{D}_{2} \mathrm{O}\right)$ in a small vial container, which was then placed on a hot block at three different temperatures of 50,70 , and $90{ }^{\circ} \mathrm{C}$ for over $3 \mathrm{~h}$. The mixed solution after ageing was then transferred from the vial container to an NMR tube. The NMR tube was inserted into the NMR for scanning. The data for initial degree of hydrolysis were analysed in terms of the identification of the peak area assigned to the functional group and further processed used Bruker Topspin 3.5 software.

Then, to speed up the analysis in stage 2, the Fourier transform infrared (FTIR) analytical technique was used instead to measure the change in degree of hydrolysis after ageing. Each aged PAM solution was cast into a watch glass and allowed to dry before being placed on a Perkin Elmer spectrum 100 FTIR-ATR spectrometer sensor for recording. In Perkin Elmer spectrum 100 FTIR, there is an attached diamond ATR crystal material, where the samples are placed and an arm is screwed down onto the sample for enhancing perfect contact to the diamond phase. Then, the spectrum will begin to appear on the computer screen, continue screwing until a good spectrum is obtained. The resolution of FTIR spectra recorded wave numbers ranging from $650-4000 \mathrm{~cm}^{-1}$ with 32 average scans. The absolute measurement provided by the ${ }^{1} \mathrm{H}$ NMR for the time zero samples was used as a calibration point for the change in absorbance measurements obtained from the FTIR in order to derive the absolute degree of hydrolysis of the aged polymer samples.

\section{Results and Discussion}

\subsection{Degree of hydrolysis of PAM in Thermally Aged Samples}

The rate of hydrolysis of amide groups has been found to be the primary mechanism behind polyacrylamide (PAM) degradation [19]. Later interactions between the hydrolyzed polyacrylamide and saline solutions containing divalent ions could cause significant losses in solution viscosity. However, the rate of hydrolysis was found to depend mostly on temperature.

\subsubsection{FTIR Measurements to Determine the Change in Degree of Hydrolysis in the Aged Samples}

Previous studies [24-26] have proposed that data on the proportion of amide $\left(\mathrm{CONH}_{2}\right)$ groups converted to carboxylate $\left(\mathrm{COO}^{-}\right)$could be used to determine the degree of hydrolysis (DH). FTIR can be used to monitor the change in absorbance associated with the stretching of the secondary amide $\left(\mathrm{CONH}_{2}\right) \mathrm{C}=\mathrm{O}$ to give a measure of the change in degree of hydrolysis of the amide group.

Emission or absorption spectra arise when PAM molecules undergo transitions between quantum states corresponding to internal energy levels. In infrared spectroscopy, the presence of different functional groups results in the absorption of energy at specific wavelengths and its re-transmission results in the formation of peaks. Table 2 shows the assignment of the FTIR characterization of the bands and spectra of PAM.

Primary amide $\mathrm{NH}_{2}$ symmetric stretching occurred at $3190-3170 \mathrm{~cm}^{-1}$ and the asymmetric stretching band of $\mathrm{NH}_{2}$ appeared at $3340-3332 \mathrm{~cm}^{-1}$. A combination of these two peaks was used to determine the transmittance of the amide group. Secondary amide $\mathrm{N}-\mathrm{H}$ stretching was observed at $3300-3250 \mathrm{~cm}^{-1}$ with a corresponding secondary amide II overtone. The primary amide $\mathrm{C}=\mathrm{O}$ stretching $\left(\mathrm{CONH}_{2}\right)$ was assigned in a shift range of $1680-1630 \mathrm{~cm}^{-1}$. The vibrational modes of amide groups may be affected as a result of hydrogen bonding. Therefore, the secondary amide $\mathrm{C}=\mathrm{O}$ stretching $\left(\mathrm{CONH}_{2}\right)$ was assigned at a point between $1630-1603 \mathrm{~cm}^{-1}$.

Four significant peaks for carboxylate groups were observed at $1330-1600 \mathrm{~cm}^{-1}$ as a result of the stretching of acrylate. The vibration on the band shifted at C-O stretching at around $1200-1300 \mathrm{~cm}^{-1}$; the vibrations also existed in plane bending around $1000-1300 \mathrm{~cm}^{-1}$ and out-of-plane bending at 
$900-992 \mathrm{~cm}^{-1}$. Figure $2 \mathrm{a}, \mathrm{b}$ present the percentage transmittance versus wave-number for PAM solutions in pure water and brine.

Table 2. Assignment of the Fourier transform infrared (FTIR) characterization of bands of the polyacrylamide (PAM).

\begin{tabular}{cc}
\hline Frequency & Assignment \\
\hline $3340-3332$ & Primary amide $\mathrm{NH}_{2}$ asymmetric stretching \\
$3300-3250$ & Secondary amide $\mathrm{N}-\mathrm{H}$ stretching \\
$3190-3170$ & Primary amide $\mathrm{NH}_{2}$ symmetric stretching \\
$3100-3060$ & Secondary amide II overtone \\
$1680-1630$ & Primary amide $\mathrm{C}=\mathrm{O}$ stretching \\
$1630-1603$ & Secondary amide C=O stretching \\
\hline & Carbonyl Containing Compound
\end{tabular}

The major bands that appear in the infrared spectra of carboxylic acids (which contain the $\mathrm{COOH}$ group) summarized below:

\begin{tabular}{cc}
\hline $1603-1330$ & $\mathrm{COO}^{-}$stretching \\
$1330-1300$ & $\mathrm{C}-\mathrm{O}$ stretching \\
$1300-1000$ & $\mathrm{C}-\mathrm{O}-\mathrm{H}$ in plane bending \\
$900-992$ & $\mathrm{C}-\mathrm{O}-\mathrm{H}$ out of plane bending \\
\hline
\end{tabular}

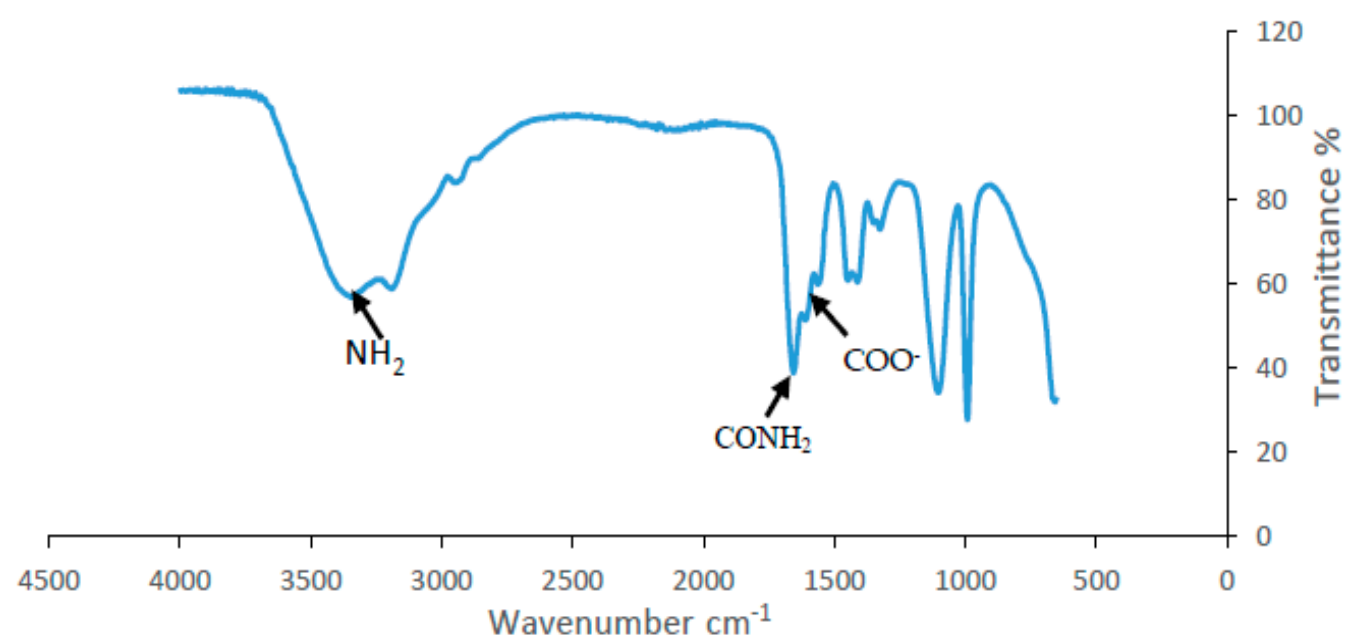

(a)

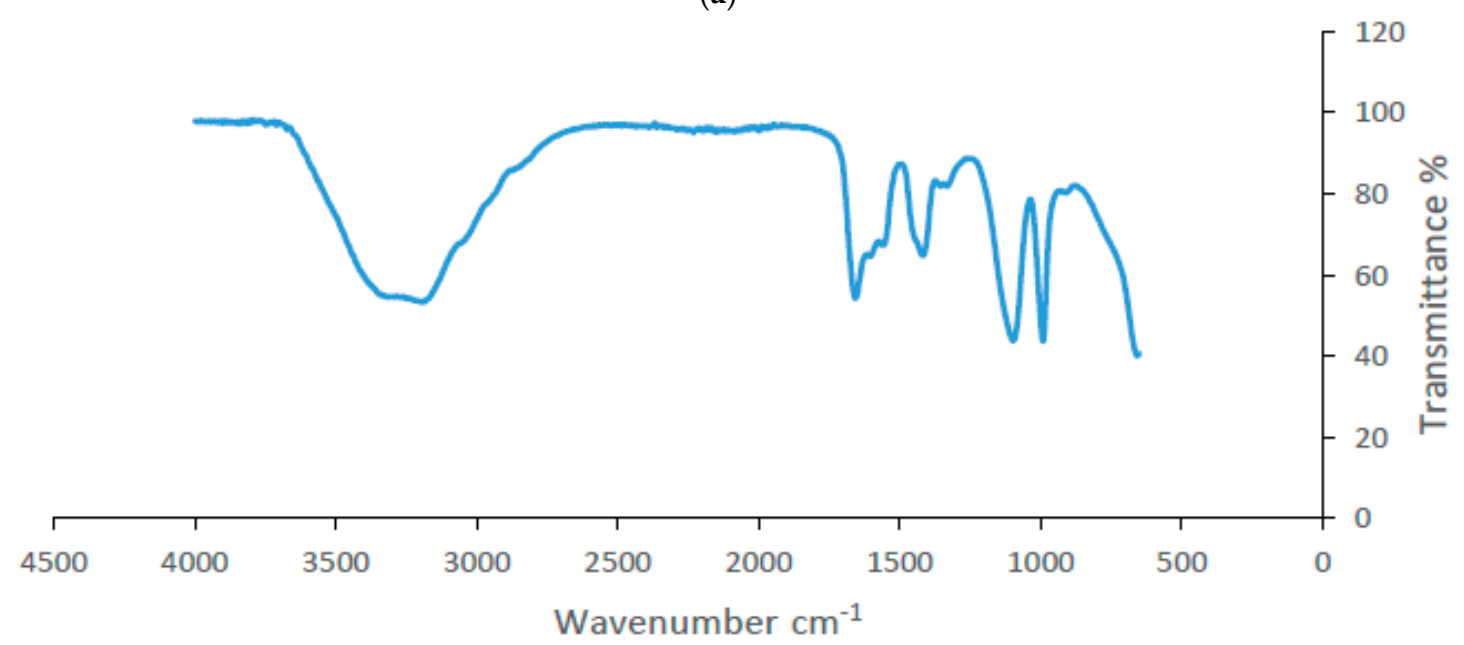

(b)

Figure 2. Fourier transform infrared (FTIR) spectra of PAM in pure water (a) and brine (b). 
To be of use, the value of transmittance is transformed into absorbance using Equation (1) [27]. The amide group content of the hydrolysed polyacrylamide was determined from the intensities of absorbance in the amide group $\left(\mathrm{CONH}_{2}\right)$.

$$
\mathbf{A}=-\log \frac{\% T}{100}
$$

These results are presented in Figure 3a,b.

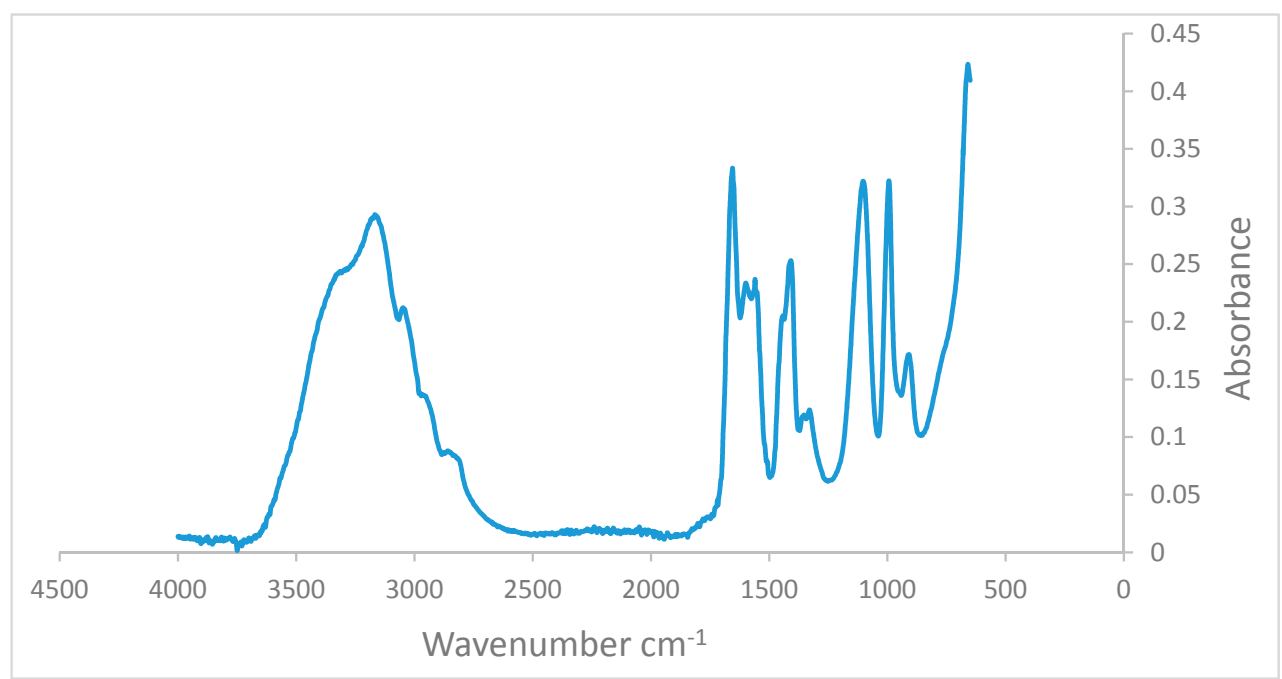

(a)

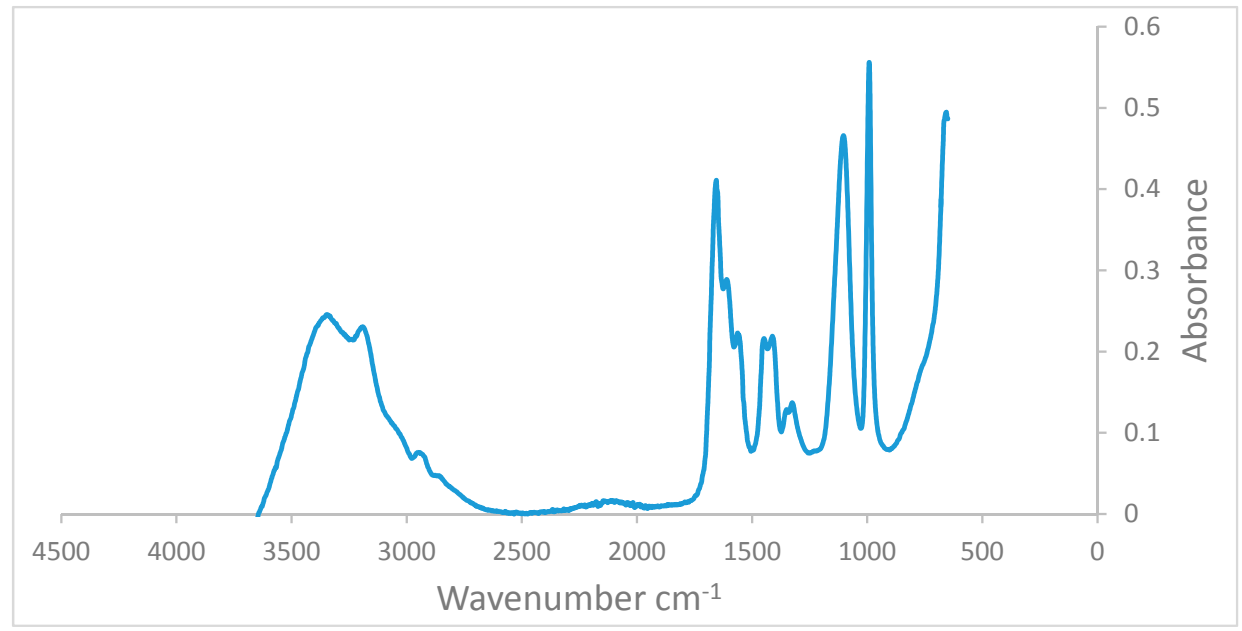

(b)

Figure 3. (a) FTIR spectra absorbance of PAM at $50{ }^{\circ} \mathrm{C}$ in pure water. (b) FTIR spectra absorbance of $\mathrm{PAM}$ at $50^{\circ} \mathrm{C}$ in brine.

The percentage increase in amide absorbance is equal to the difference between the initial amide absorbance at day zero $\left(A_{0}\right)$ and each amide absorbance at the designated ageing times $\left(A_{1,2,4 \ldots 30}\right)$ over the initial amide absorbance expressed as a percentage, as shown in Equation (2):

$$
\text { Percentage change in Absorbance }(\%)=\frac{A_{1,2,4 \ldots 30}-A_{0}}{A_{0}} \times 100
$$

Figure 4a-c present the percentage change in absorbance of amide groups $\left(\mathrm{CONH}_{2}\right)$ against ageing time in days at 50,70 , and $90^{\circ} \mathrm{C}$. As shown in these figures, the percentage of amides at 50, 70, and $90{ }^{\circ} \mathrm{C}$ increases from 18 to $30 \%$, from 33 to $57 \%$, and from 48 to $57 \%$ at the different temperatures. 


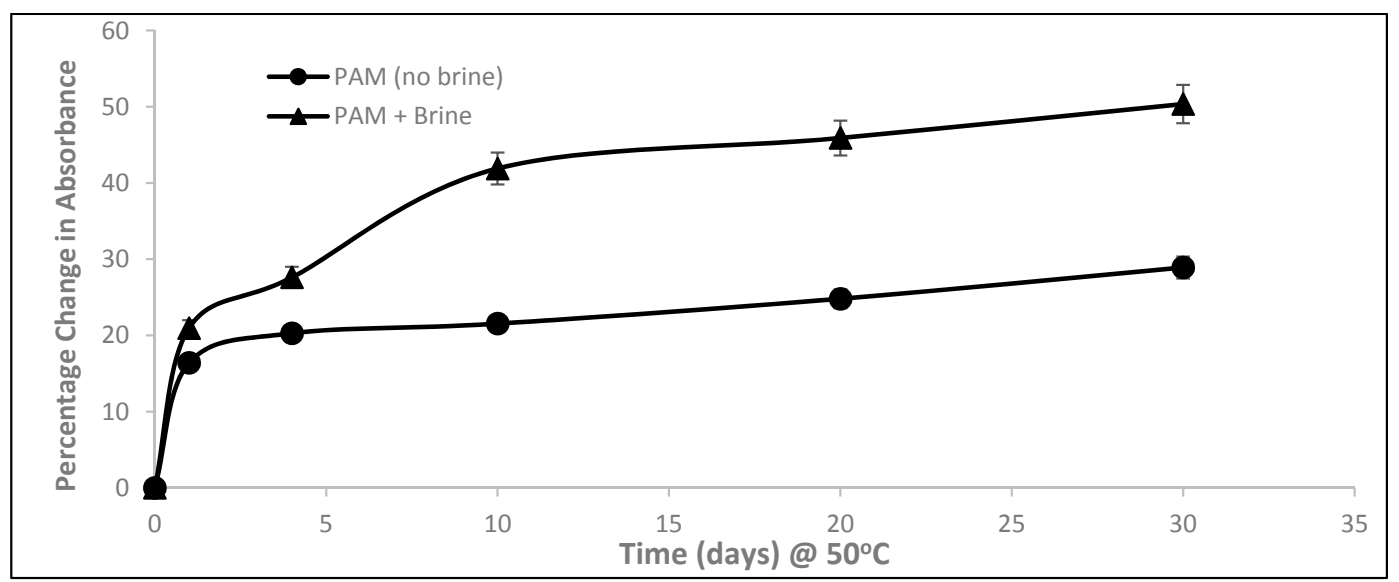

(a)

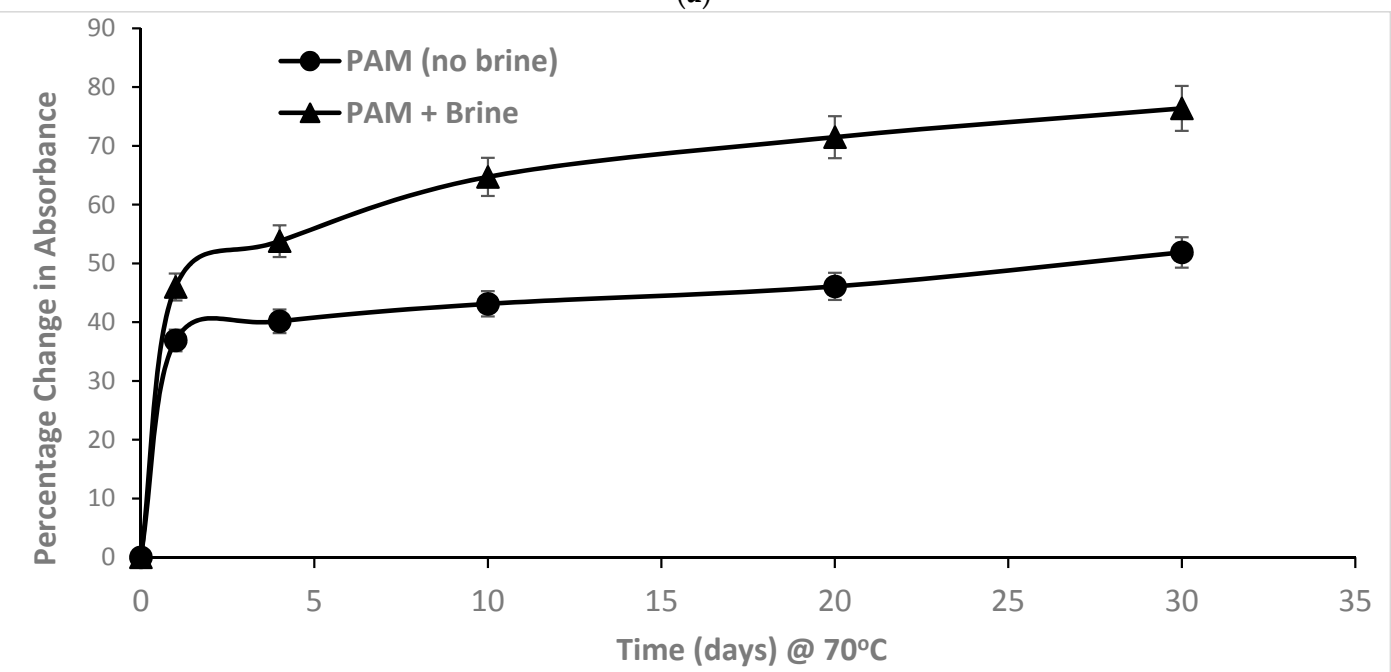

(b)

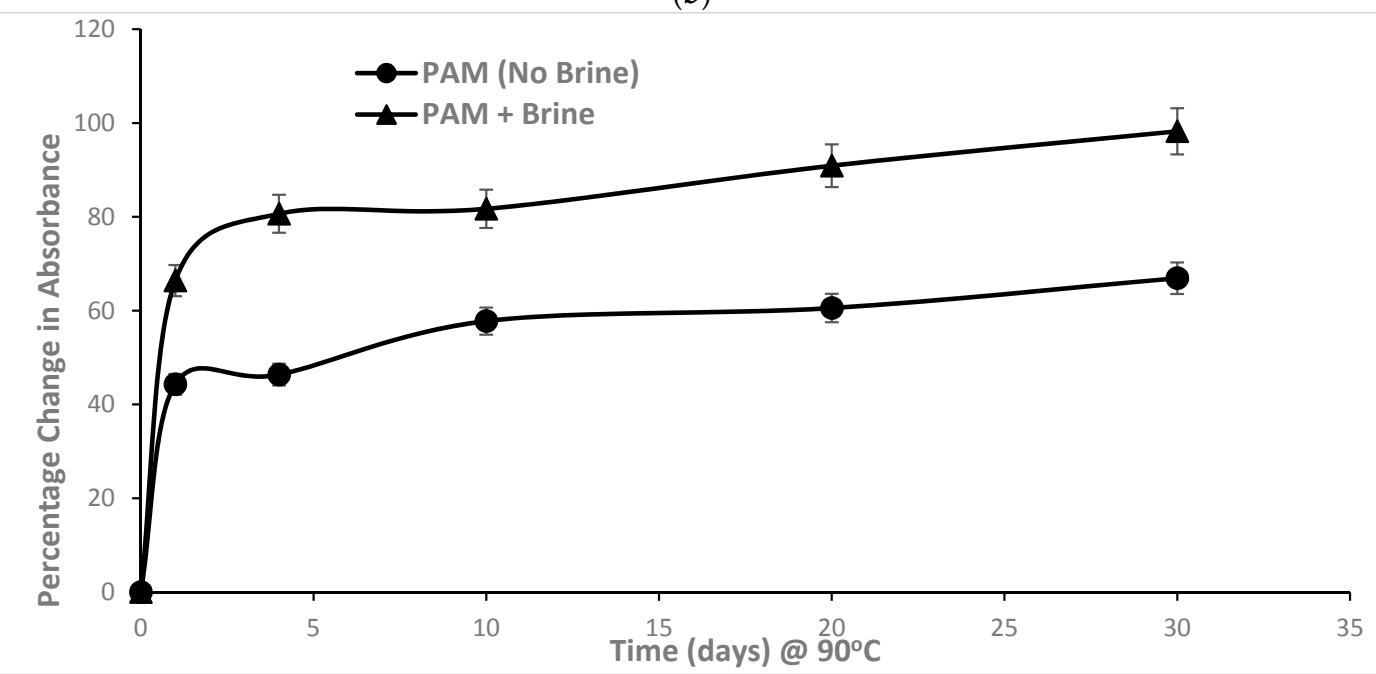

(c)

Figure 4. (a) Percentage change in absorbance in PAM solution in presence of and without brine at $50{ }^{\circ} \mathrm{C}$; (b) percentage change in absorbance in PAM solution in presence of and without brine at $70{ }^{\circ} \mathrm{C}$; (c) percentage change in absorbance in PAM solution in presence of and without brine at $90{ }^{\circ} \mathrm{C}$.

These results prove that the percentage change in the absorbance of amide groups present in PAM increases as temperature increases, indicating that temperature is the major driving force in the 
degradation of PAM. In the presence of brine, the amide group in PAM is further hydrolysed, where at the same temperature conditions as in the absence of brine, the percentage of amide groups increased from 25 to $61 \%$, from 38 to $75 \%$, and from 62 to $88 \%$, respectively, at the three different temperatures. Therefore, the interaction of PAM with brine at 50,70 , and $90{ }^{\circ} \mathrm{C}$ shows greater percentage increases in amide groups in the solutions compared with that when brine is not present.

\subsubsection{NMR Measurements on Time Zero Samples}

The rate of hydrolysis of amide groups was found to be primary mechanism behind PAM degradation. In order to determine the degree of hydrolysis, Figure 5 illustrates the ${ }^{1} \mathrm{H}$ NMR spectra for PAM dissolved in pure water and brine.

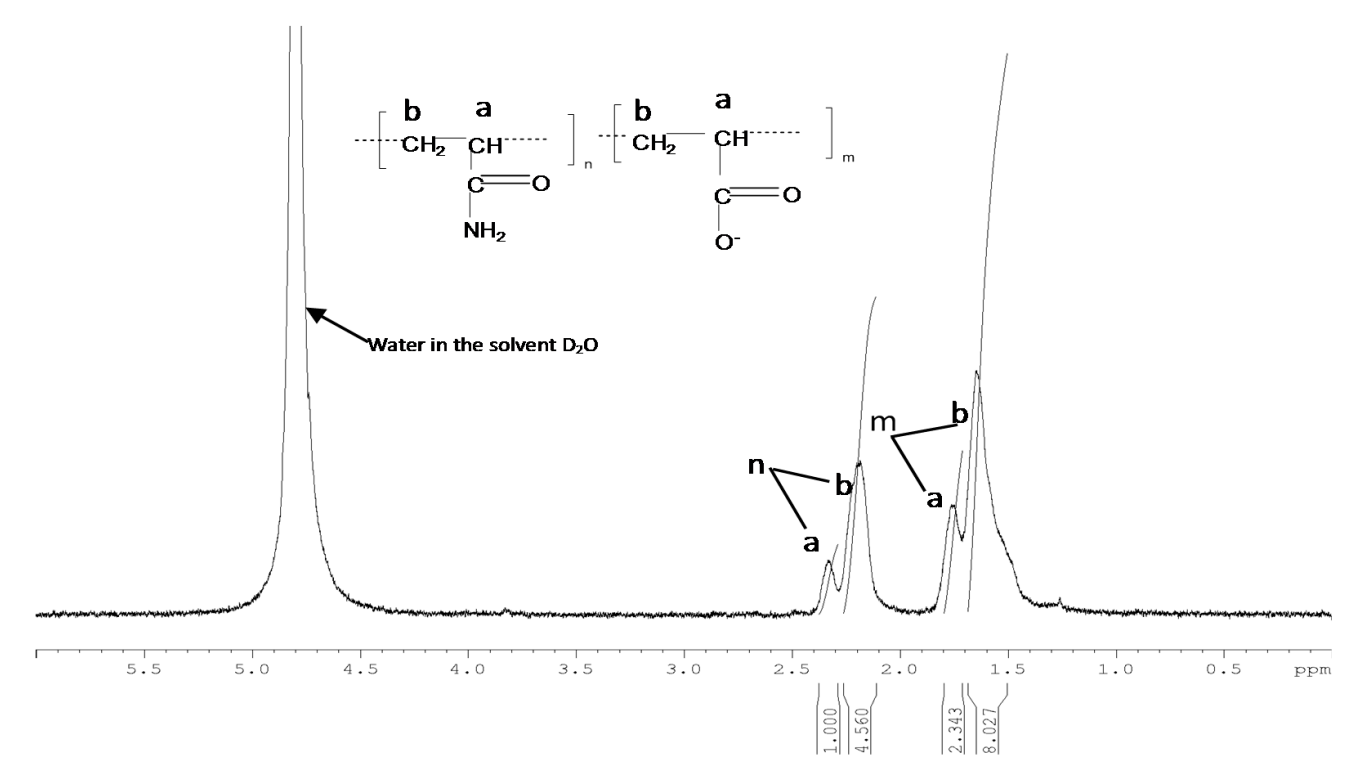

(a)

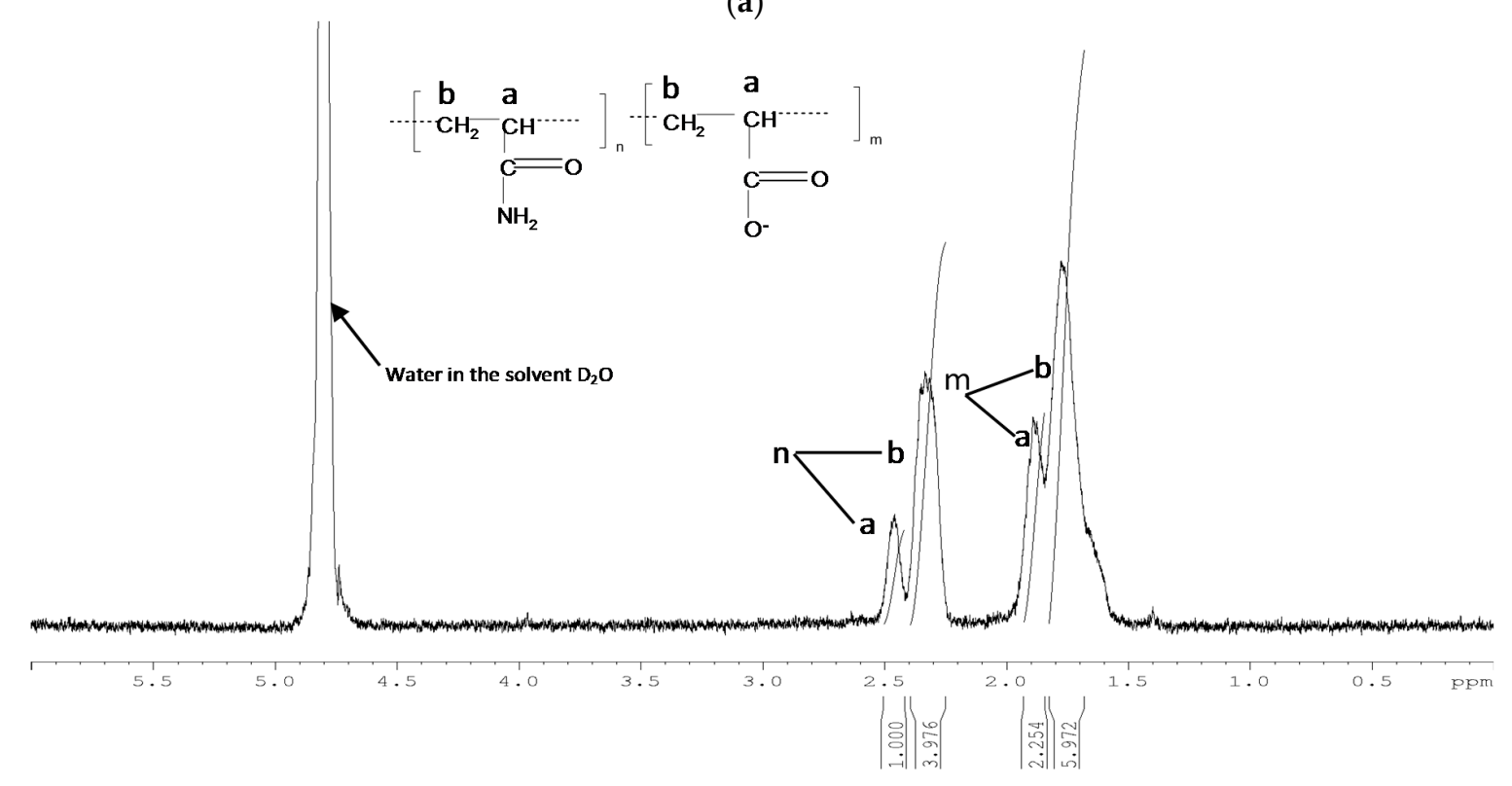

(b)

Figure 5. ${ }^{1} \mathrm{H}$ NMR spectra: (a) PAM dissolved in pure water; (b) PAM dissolved in brine.

In these two scans, the first peak positioned at $4.8 \mathrm{ppm}$ represents water content in the deuterium oxide solvent. The peaks measured at $2.20-2.40$ and $1.60-1.80 \mathrm{ppm}$ represent the amide $\left(\mathrm{CONH}_{2}\right)$ 
and carboxylate $\left(\mathrm{COO}^{-}\right)$groups, respectively [26]. The determination of degree of hydrolysis was performed by processing the calibration axis and integration of the peak area using Bruker Topspin 3.5 software.

The integral values indicate the total amount of hydrogen $(\mathrm{H})$ atoms within the molecular structure, and this helps in identifying the functional group, such as $\mathrm{CH}, \mathrm{CH}_{2}$, and $\mathrm{CH}_{3}$. The degree of hydrolysis (DH) was calculated using Equation (3).

$$
D H(\%)=\frac{n_{a}}{m_{a}+n_{a}} \times 100
$$

where $n_{a}$ is the position of the amide groups $\left(\mathrm{CONH}_{2}\right)$ on the peak shift as assigned by the hydrogen atom in $\mathrm{CH}$, and $m_{a}$ is the position of the carboxylate group $\left(\mathrm{COO}^{-}\right)$in the peak shift as assigned by the hydrogen atom in $\mathrm{CH}$.

The degrees of hydrolysis of the initial samples for PAM dissolved in both pure water and brine are recorded in Table 3.

Table 3. Initial degree of hydrolysis $\left(D H_{i}\right)$ for pure water and brine samples.

\begin{tabular}{ccc}
\hline Temperature & $\mathbf{D H}_{\boldsymbol{i}}$ (Pure Water $)$ & $\mathbf{D H}_{\boldsymbol{i}}$ (Brine) \\
\hline $50{ }^{\circ} \mathrm{C}$ & $30 \%$ & $34 \%$ \\
$70{ }^{\circ} \mathrm{C}$ & $31 \%$ & $37 \%$ \\
$90^{\circ} \mathrm{C}$ & $33 \%$ & $38 \%$ \\
\hline
\end{tabular}

For the initial samples at time zero, it is clear that the degree of hydrolysis rises with temperature for both sets of samples. The degree of hydrolysis for the brine dataset is systematically higher than that for the samples prepared in pure water.

To convert the percentage absorbance change into degree of hydrolysis, the percentage increases in amide groups and the initial degree of hydrolysis $(\mathrm{DH})$ are combined and the final equation is expressed in Equation (4).

$$
D H_{t}=\frac{100+\% \mathrm{CONH}_{2}}{100} \times D H_{i}
$$

where $\mathrm{DH}_{t}$ is the degree of hydrolysis at each designated time, $\mathrm{DH}_{i}$ is the initial degree of hydrolysis at day zero from the ${ }^{1} \mathrm{H}$ NMR analysis, and $\% \mathrm{CONH}_{2}$ is the percentage change in absorbance.

Figure $6 \mathrm{a}, \mathrm{b}$ show the final degree of hydrolysis of PAM plotted as a function of ageing time in pure water and brine, respectively.

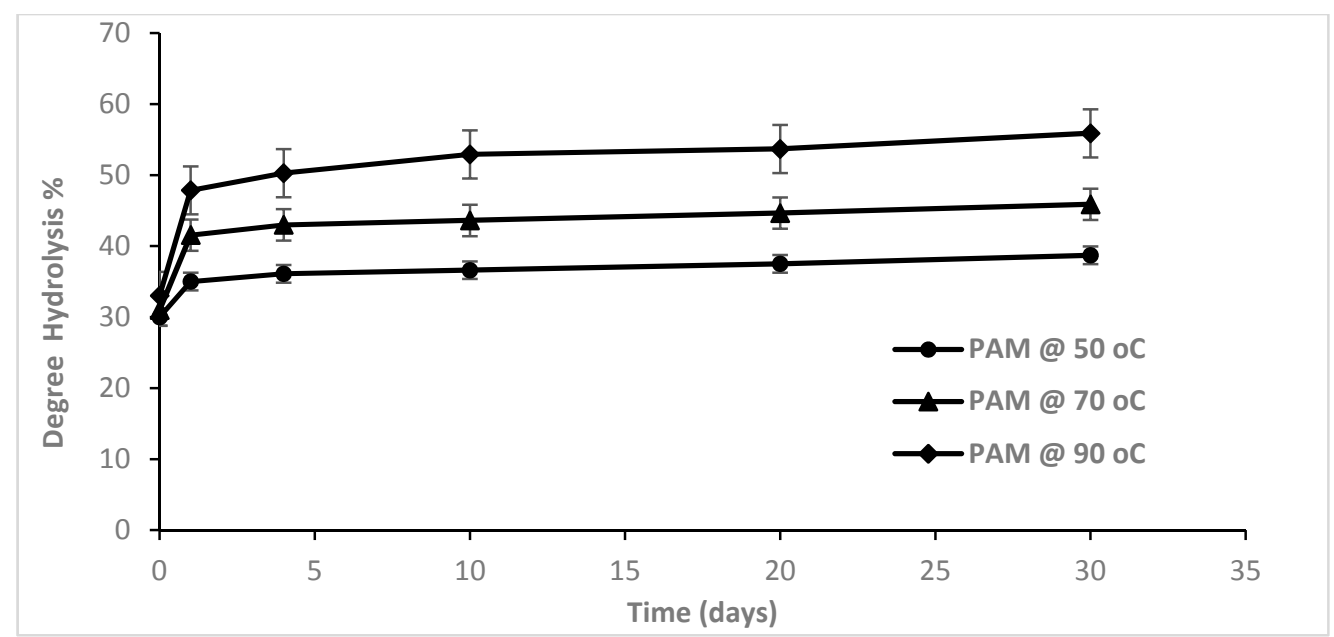

(a)

Figure 6. Cont. 


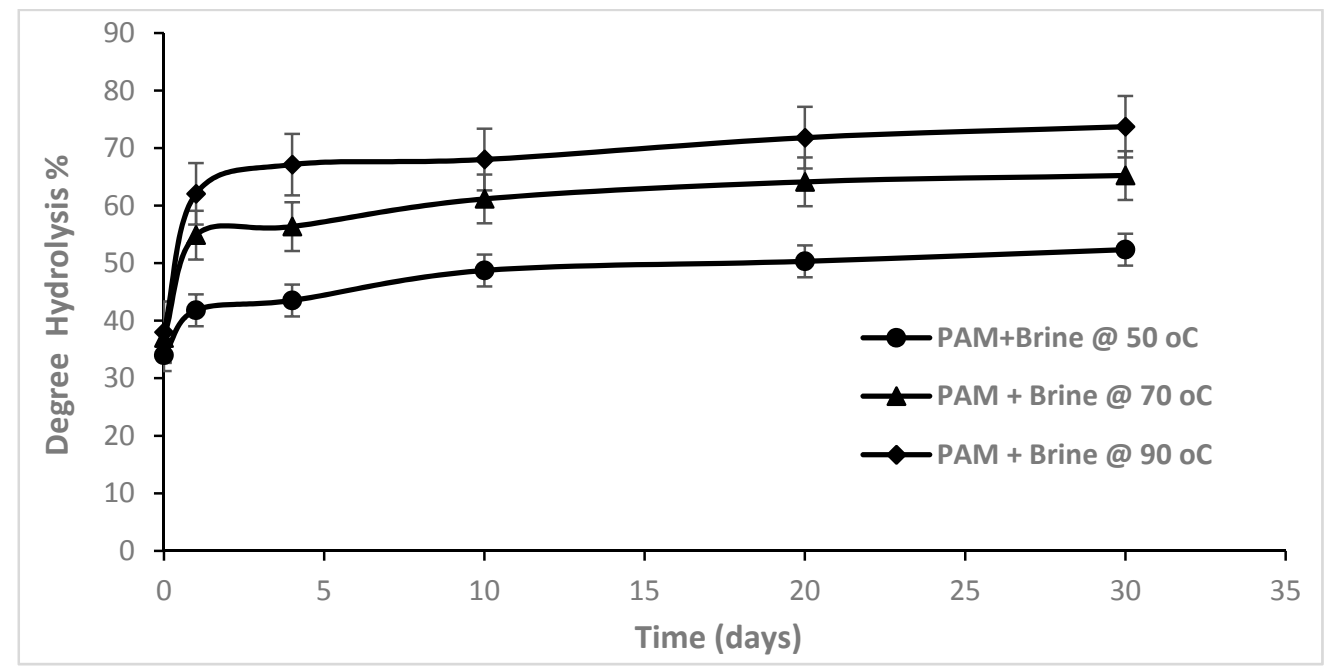

(b)

Figure 6. (a) Degree of hydrolysis of PAM in pure water at temperature of 50, 70, and $90{ }^{\circ} \mathrm{C}$; (b) degree of hydrolysis of PAM in brine at temperature of 50,70 , and $90^{\circ} \mathrm{C}$.

Figure 6a provides evidence of the degree of hydrolysis against ageing time for PAM mixed in pure water. As seen in this figure, temperature and ageing time are the main factors determining the increasing degree of hydrolysis. All samples demonstrate an increase in hydrolysis with temperature.

Using a similar approach, the degrees of hydrolysis of PAM in the presence of ions against ageing time for the temperatures studied are demonstrated in Figure $6 \mathrm{~b}$. The degree of hydrolysis in the brine solutions is systematically higher than that observed in the samples prepared in pure water. For instance, degrees of hydrolysis of about $39 \%, 46 \%$, and $56 \%$ at $50{ }^{\circ} \mathrm{C}, 70{ }^{\circ} \mathrm{C}$, and $90{ }^{\circ} \mathrm{C}$, respectively, for PAM solution in pure water increased after ageing up to 30 days to values of about $52 \%, 65 \%$, and $74 \%$, respectively, in brine solution.

All records show two distinct phases of hydrolysis. In phase one (0-1 day), the degree of hydrolysis rises very quickly. In phase two, the rate of change in degree of hydrolysis is reduced significantly and the trend takes a linear form.

\subsection{Rheological Characterization of PAM}

The viscosity of the displacing fluid is a necessary criterion for screening an injection fluid during chemical flooding, because an optimal viscosity of the displacing fluid is required to ensure favourable mobility so as to achieve better oil recovery with good injectivity at lower $\operatorname{cost}^{1}$. The viscous behaviour of PAM at different temperatures and salinities was measured in terms of its thermal stability, where the estimation detected two types of rheological behaviour: thixotropic and pseudo-plastic.

\subsubsection{Time-Dependent Effects on Thermal Stability of PAM Viscosity}

As discussed in Section 3.1, PAM solutions at high temperature experience a higher degree of hydrolysis, leading to an increase in anionicity that could result in instability in the behaviour of the gel. When the degree of hydrolysis is above $33 \%$, polymer degradation or precipitation may occur at high temperatures [18]. PAM exhibits thixotropic behaviour where solution viscosity tends to decrease at a constant shear rate during some extended test period [28]. Figure 7 presents the measured viscosity levels of PAM solution at $50{ }^{\circ} \mathrm{C}$ in the presence and absence of brine for low shear rates of 10 and $30 \mathrm{rpm}$ and high shear rates of $600 \mathrm{rpm}$. The results show a steady decrease in viscosity for the lower shear rates, while the decrease is sharper for higher shear rates. It is worth mentioning that, at higher shear rates, much of the decrease in viscosity occurred after 10 days of ageing and, after that, no significant change in viscosity was observed. 


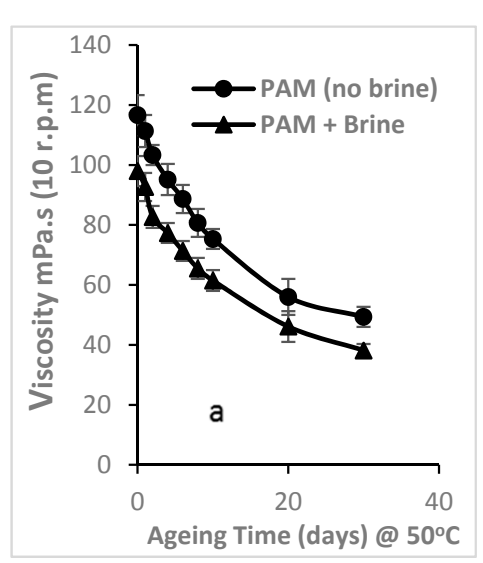

(a)

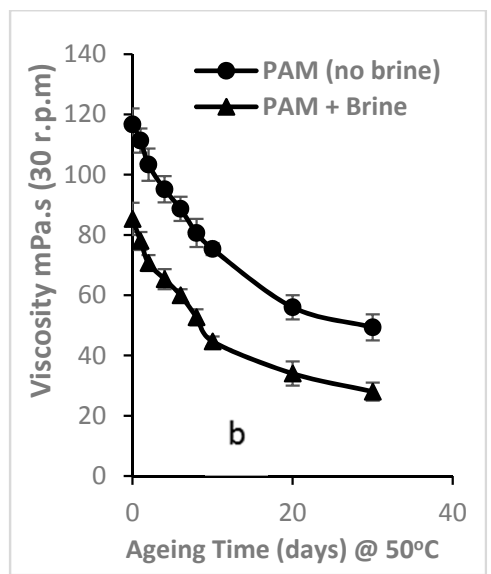

(b)

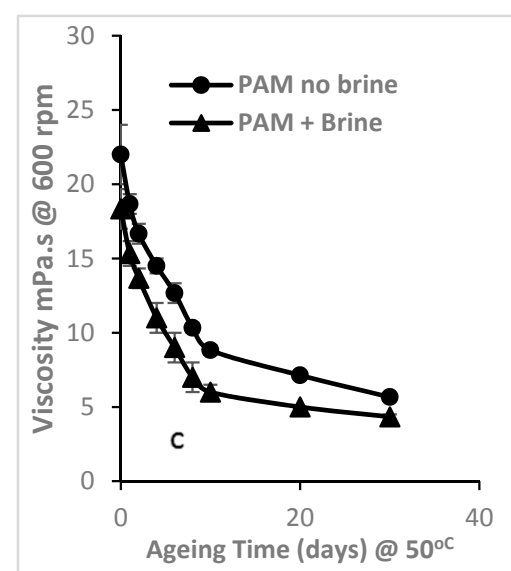

(c)

Figure 7. Thixotropic behaviour of PAM at $50{ }^{\circ} \mathrm{C}$ at low rotational speeds of (a) $10 \mathrm{rpm}$ and (b) $30 \mathrm{rpm}$, as well as at a high rotational speed of (c) $600 \mathrm{rpm}$.

The low shear rate at $10 \mathrm{rpm}$ leads to a steady fall in viscosity over time, while at $30 \mathrm{rpm}$, a similar trend is observed but with a slightly larger fall in viscosity. The high shear rate at $600 \mathrm{rpm}$ gives a much larger overall fall in viscosity, which seems to take place in two stages. Accordingly, in stage 1 , a rapid fall over the first 10 days starts to level off over the remaining time, and this is suggestive of shear thinning behaviour and the collapse of the gel structure.

The same approach was adopted for the higher temperatures, and the data are reported in Figures 8 and 9 .

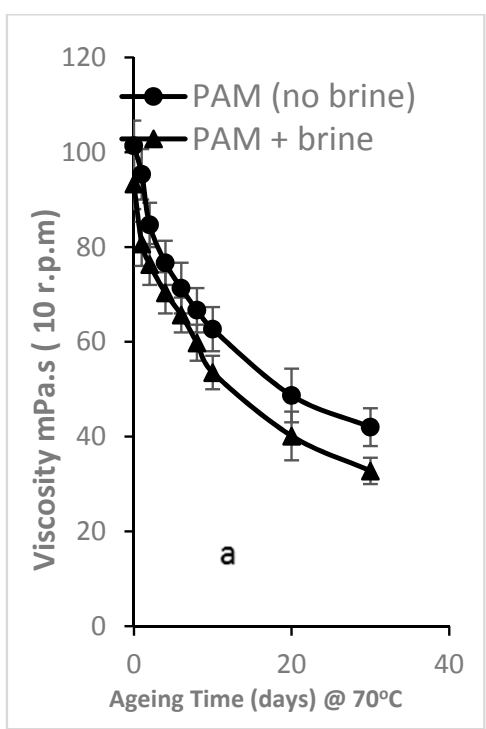

(a)

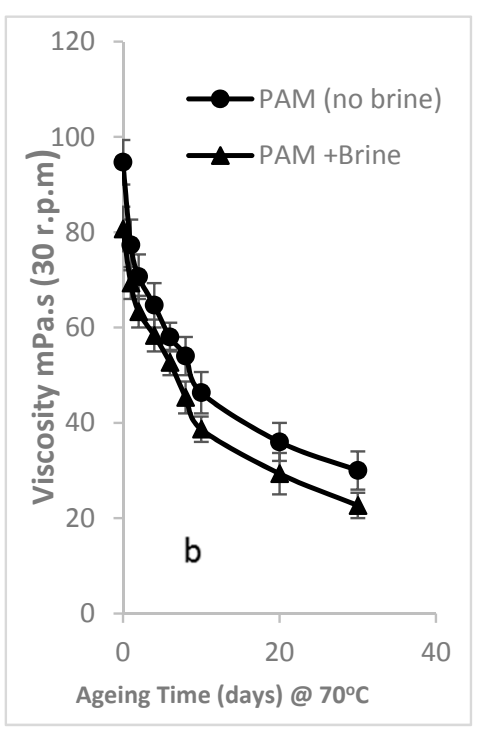

(b)

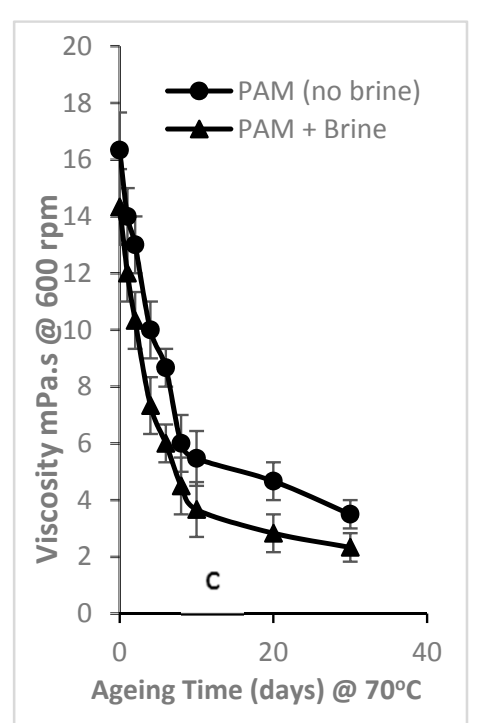

(c)

Figure 8. Thixotropic behavior of PAM at $70{ }^{\circ} \mathrm{C}$ at low rotational speeds of (a) $10 \mathrm{rpm}$ and (b) $30 \mathrm{rpm}$, as well as (c) at a high rotational speed of $600 \mathrm{rpm}$.

As can be seen from Figures 7-9, the rate of fall in viscosity increased with temperature for the PAM solutions in the presence of brine. At $90{ }^{\circ} \mathrm{C}$, the transition to stage 2 behaviour occurred at $30 \mathrm{rpm}$, indicating that gel collapse is accelerated at higher temperatures and lower rotational speeds. 


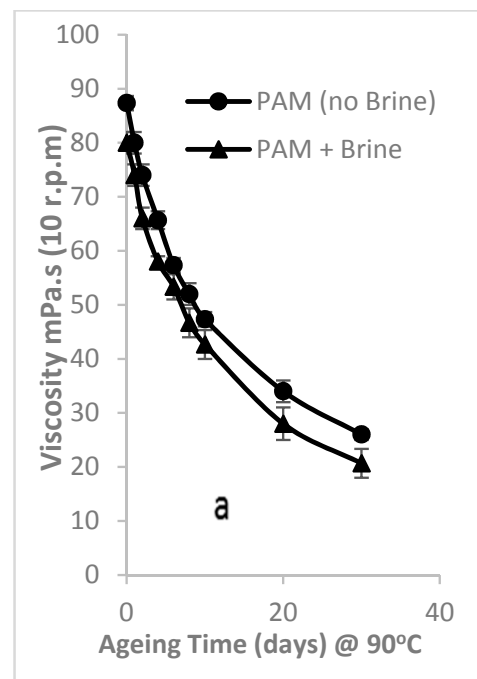

(a)

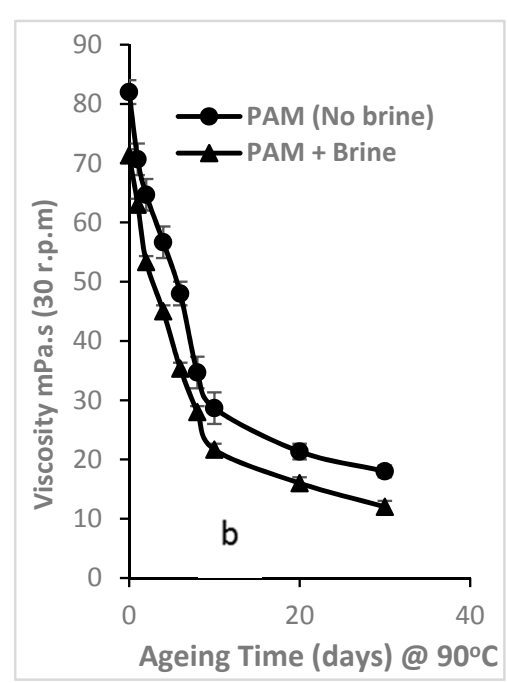

(b)

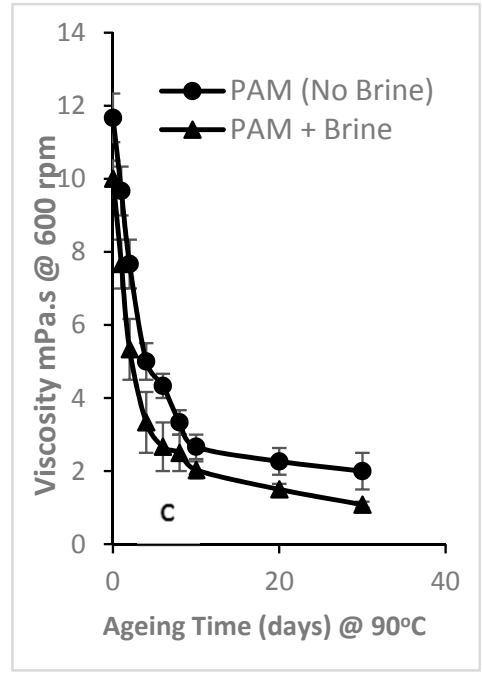

(c)

Figure 9. Thixotropic behavior of PAM at $90^{\circ} \mathrm{C}$ at low rotational speeds of (a) $10 \mathrm{rpm}$ and (b) $30 \mathrm{rpm}$, as well as at (c) a high rotational speed of $600 \mathrm{rpm}$.

\subsubsection{Percentage Change in Viscosity of PAM Solution}

In the application of polyacrylamide in oilfields, it is of primary importance to ensure that the polymer solution remains effective over long periods at different temperatures. To determine the loss of viscosity of the PAM solution, combined operational conditions of shear rate, time, brine content, and temperature $\left(50^{\circ} \mathrm{C}, 70{ }^{\circ} \mathrm{C}\right.$, and $\left.90^{\circ} \mathrm{C}\right)$ were analyzed using Equation (5):

$$
\text { Loss of viscosity (\%) of PAM solution }=\frac{V_{0}-V_{\mathrm{n}}}{V_{0}} \times 100
$$

where $V_{0}$ is the initial polymer solution viscosity before ageing in the oven, and $V_{n}$ is viscosity at different ageing times.

These results are shown in detail in Figure 10. At all temperatures and rotational speeds, it was observed that the longer the ageing time of PAM solution in either pure water or brine, the greater the loss of PAM viscosity. For instance, at the higher temperature of $90{ }^{\circ} \mathrm{C}$ and with 30 days of ageing, the loss of viscosity was between $84-78 \%$ and $77-71 \%$ for PAM mixed in brine and PAM mixed in pure water, respectively. Meanwhile, at a lower temperature of $50{ }^{\circ} \mathrm{C}$, the losses in viscosity were $69-66 \%$ and $61-58 \%$, respectively.

To investigate the efficiency of PAM performance in different operational conditions, the influence of shear rate on viscosity retention needed to be checked. Tests were conducted at shear rates of 17,51 , and $1021 \mathrm{~s}^{-1}$ for temperatures of 50, 70, and $90^{\circ} \mathrm{C}$ using Equation (6):

$$
\text { viscosity retention }(\%)=\frac{V_{t}}{V_{0}} \times 100
$$

where $V_{0}=$ initial viscosity, and $V_{t}=$ viscosity at each time interval.

The results for viscosity retention at $50{ }^{\circ} \mathrm{C}, 70{ }^{\circ} \mathrm{C}$, and $90^{\circ} \mathrm{C}$ of PAM mixed with pure water and with brine under the conditions studied are presented in Figure 11. The highest degree of viscosity retention is observed for $50{ }^{\circ} \mathrm{C}$ followed by $70^{\circ} \mathrm{C}$ and $90^{\circ} \mathrm{C}$. The lower the shear rate of the PAM, the better the retention of viscosity in the solution. The presence of brine in the polymer solution led to lower retention of viscosity. The minimum retention arose in the case where PAM was mixed with brine and experienced the highest shear rate of $600 \mathrm{rpm}$ for the longest ageing time of 30 days at a higher temperature. 


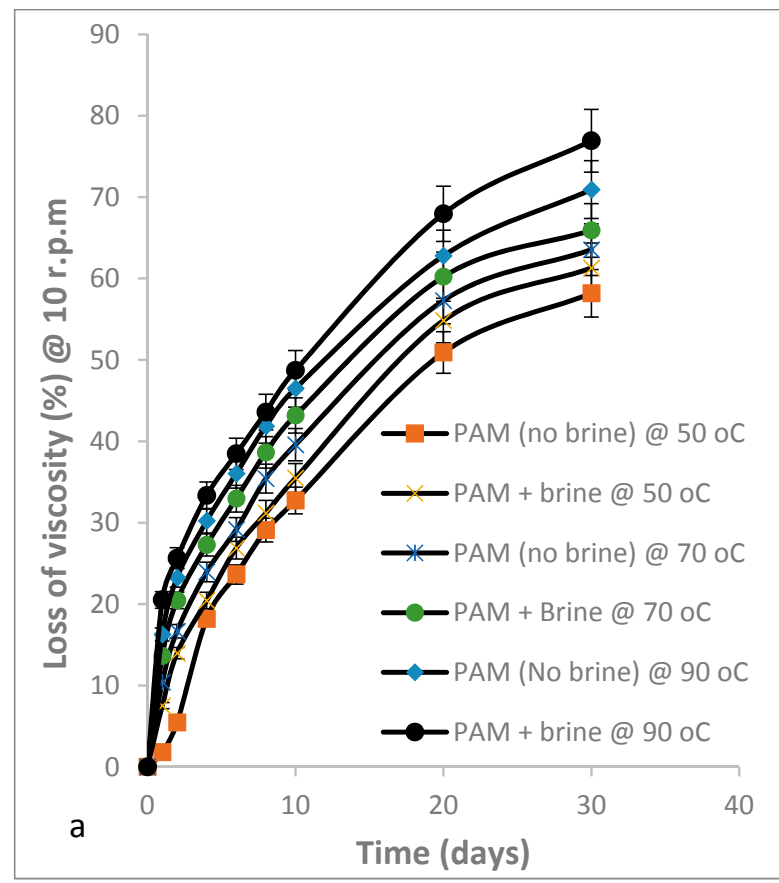

(a)

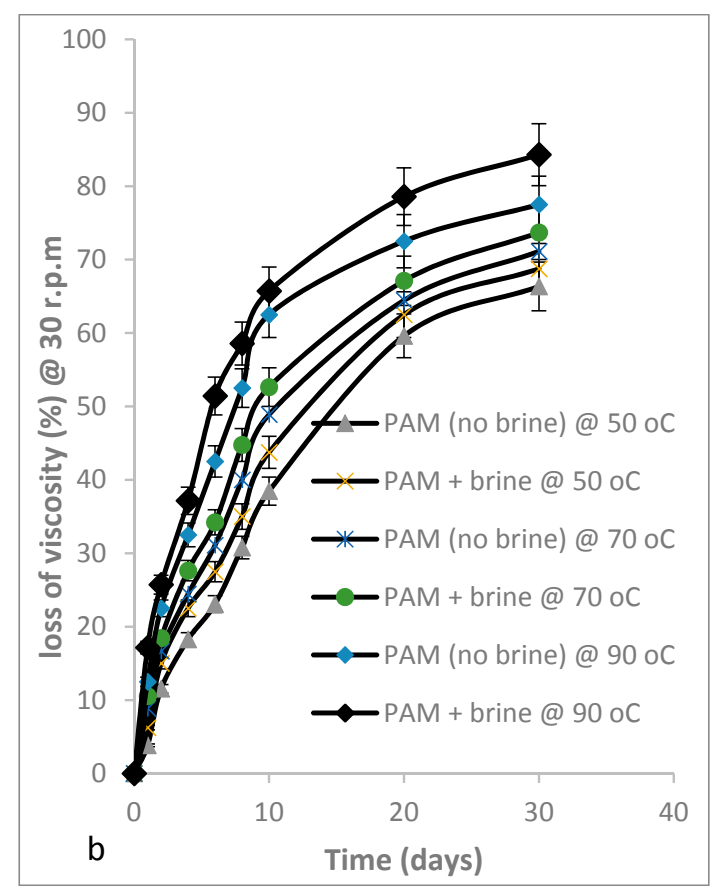

(b)

Figure 10. Percentage loss of viscosity of PAM in pure water and in the presence of brine at temperatures of 50,70 , and $90^{\circ} \mathrm{C}$ at rotational speeds of (a) $10 \mathrm{rpm}$ and (b) $30 \mathrm{rpm}$.

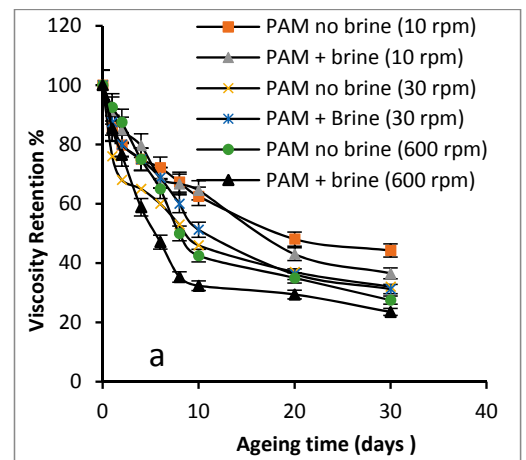

(a)

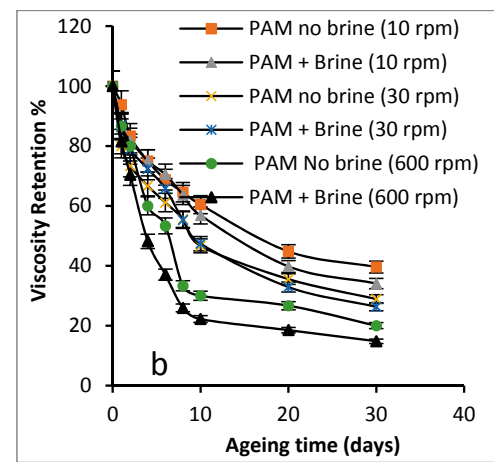

(b)

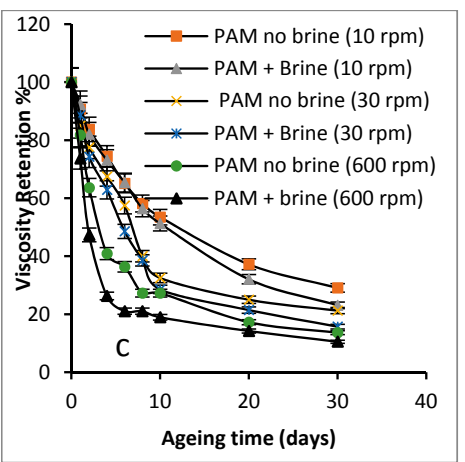

(c)

Figure 11. Viscosity retention of PAM solutions at $50{ }^{\circ} \mathrm{C}(\mathbf{a}), 70{ }^{\circ} \mathrm{C}(\mathbf{b})$, and $90{ }^{\circ} \mathrm{C}(\mathbf{c})$.

\subsubsection{Shear Dependence of the Viscosity of PAM Solution (Mechanical Degradation)}

Mechanical degradation through shearing devices can lead to significant reductions in viscosity described as a reversible decrease in viscosity with increasing shear rate (shear thinning). This behaviour of the polymer gel is known as pseudo-plastic behaviour, and it can occur when PAM solution is injected into a reservoir from the injection well [28-30]. The flow regime usually changes as the solution flows first through the wide well-bore and finally to the reservoir. Because fluid viscosity is a function of shear rate, the viscosity of the solution will also change from where it is near the well-bore compared with in the depths of a reservoir. The pseudo-plastic behaviour of PAM may also occur in pipes and through chokes, valves, or pumps. 
To determine the shear dependence of the viscosity of PAM solution when the polymer is added to a water-flooding operation, tests were conducted at 50,70 , and $90{ }^{\circ} \mathrm{C}$ and at shear rates of 5,10 , $17,51,170,340,510$, and $1021 \mathrm{~s}^{-1}$. The results are shown in detail in Figures 12-14. At low shear rates, the viscosity of PAM solution is reduced less compared with at high shear rates. However, the reduction in viscosity at different shear rates proved to be affected by ageing time as well as temperature. At low temperatures and low shear, the rate of viscosity reduction was slower in contrast to at higher temperature and high shear rate. Therefore, from the rheological measurements of fluid flow described above, it is recommended that polymer flooding is performed under laminar flow conditions and at a lower operational temperature, as shearing forces and elevated temperature may degrade the polymer, and hence suppress its performance.
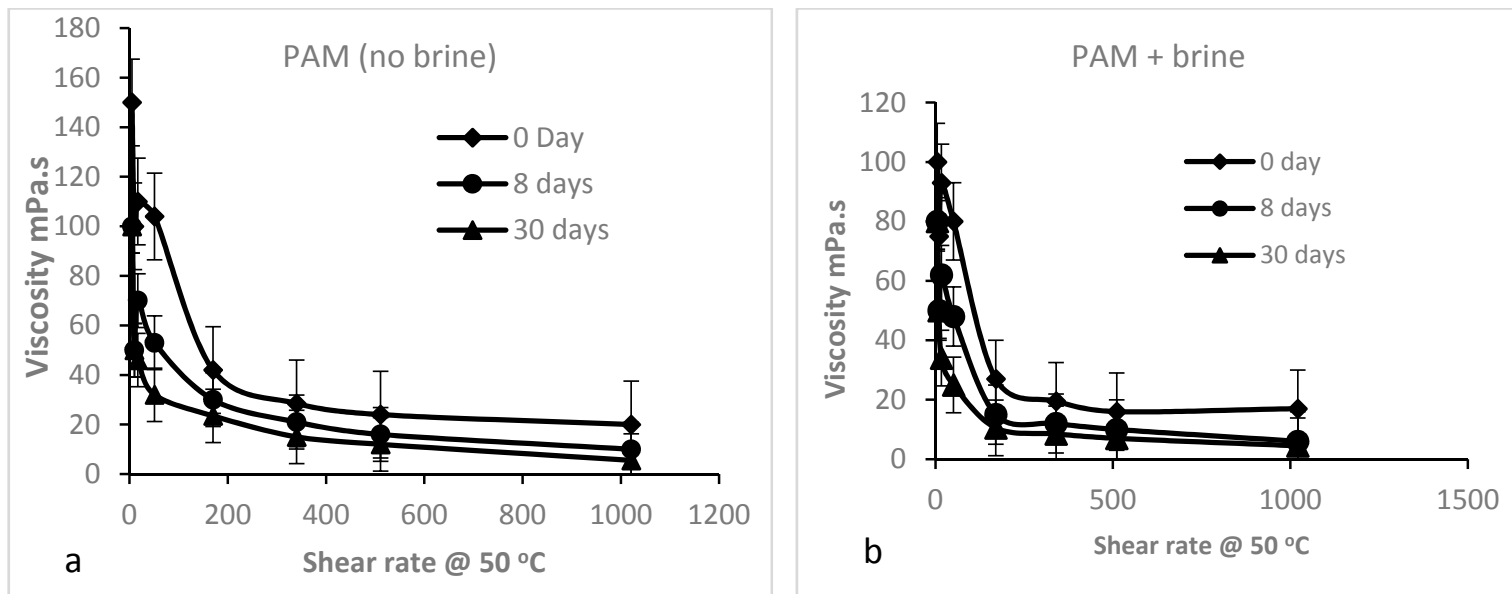

Figure 12. Mechanical degradation of PAM presented as viscosity versus shear rate at $50{ }^{\circ} \mathrm{C}$ : (a) in the absence of brine, and (b) with the presence of brine.
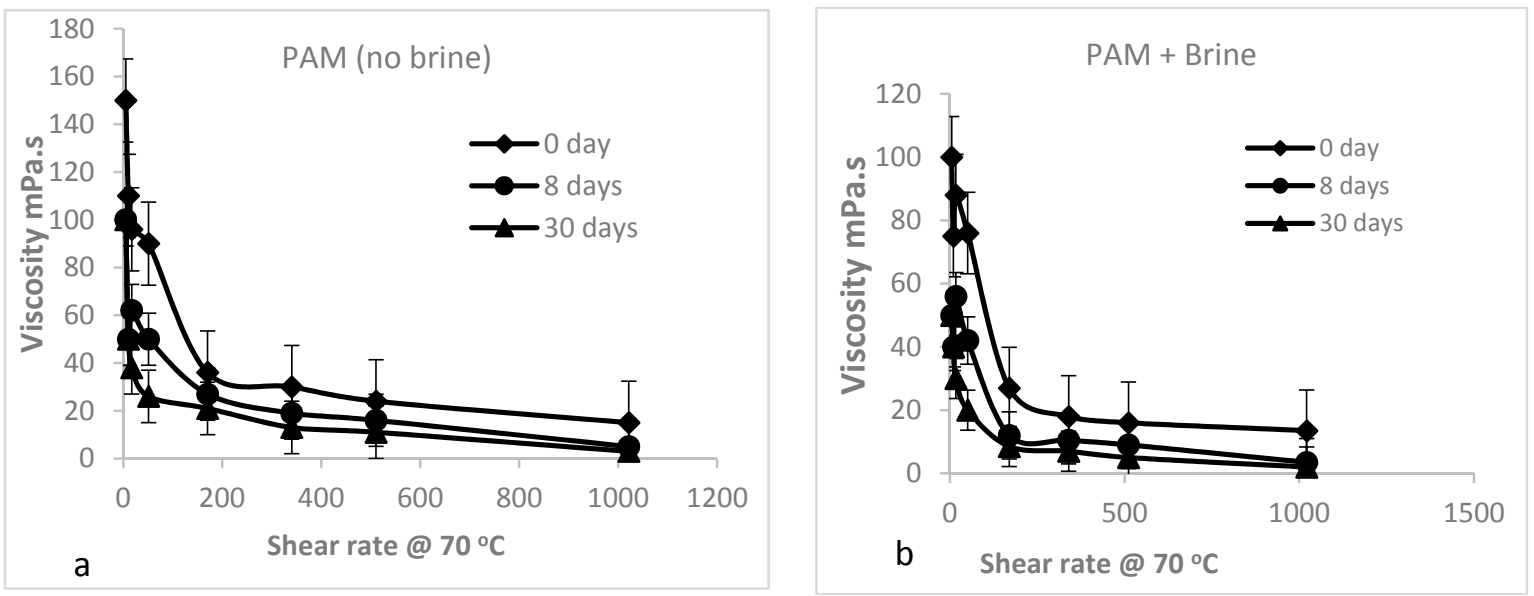

Figure 13. Mechanical degradation of PAM presented as viscosity versus shear rate at $70^{\circ} \mathrm{C}$ : (a) in the absence of brine, and (b) in the presence of brine. 

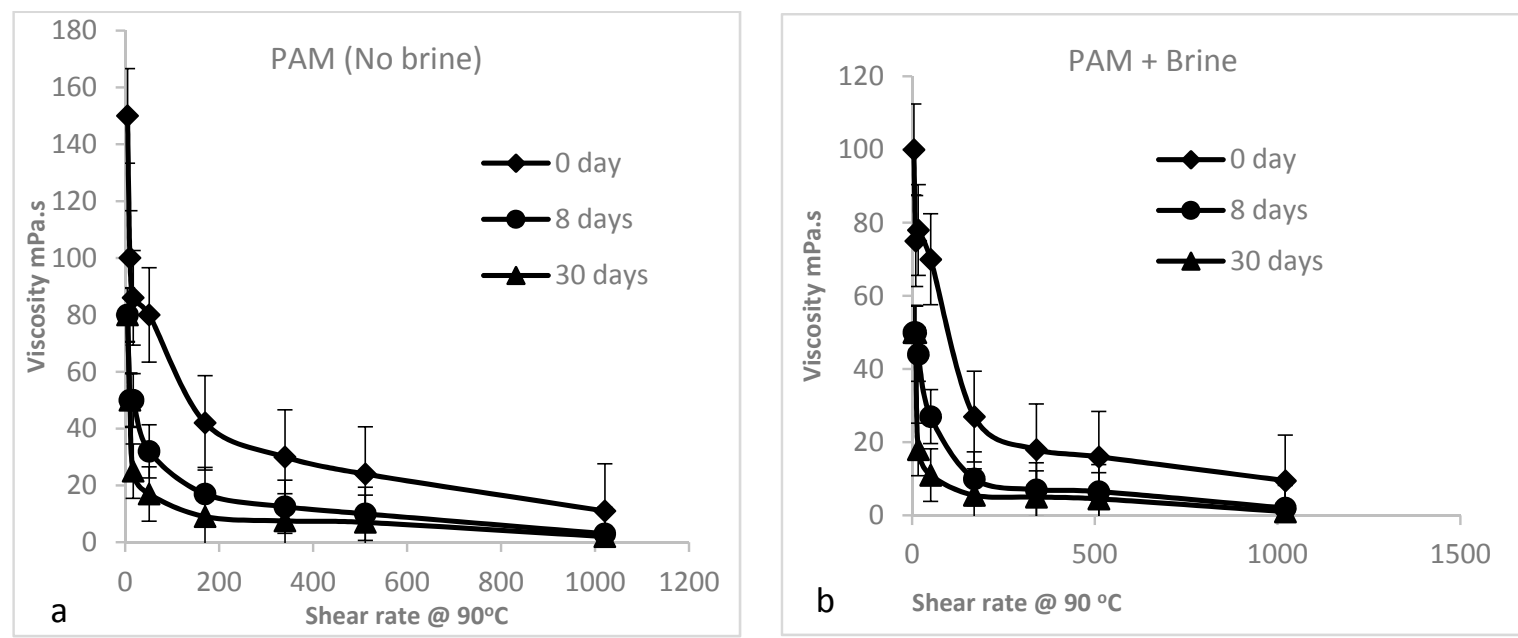

Figure 14. Mechanical degradation of PAM presented as viscosity versus shear rate at $90^{\circ} \mathrm{C}$ : (a) in the absence of brine, and (b) in the presence of brine.

\section{Conclusions}

Based on experimental studies of the effectiveness of polyacrylamide (PAM) in different operational conditions, the following conclusions can be drawn:

(1) The degree of hydrolysis of the amide groups of the PAM polymer increases with temperature. As the polymer ages, an increase in hydrolysis takes place in two stages. In stage one, a rapid rise in hydrolysis is seen over the first day. In stage two, the rate of hydrolysis is reduced and the increase is a linear function of time. With the addition of brine, a similar pattern is seen but the rate of hydrolysis in the first stage is increased.

(2) The highest viscosity retention is observed at the lowest temperature. The lower the shear rate, the better the retention of viscosity in the solution. The addition of salt to the solution leads to a decreased retention of viscosity. The minimum retention occurs in the case where PAM is mixed with brine and experiences the highest shear rate of $600 \mathrm{rpm}$ for the longest ageing time of 30 days at higher temperature.

(3) At high shear rates, the rate of fall in viscosity appears to occur in two stages, with an initial rapid fall followed by a very slow reduction after about 10 days. This suggests that the nature of the gel changes after 10 days and the gel collapses.

(4) At higher temperatures, the onset of the collapse of the gel occurs at lower shear rates. The increase in degree of hydrolysis occurs faster than the reduction in viscosity. This suggests that the degree of hydrolysis is not the only factor governing the viscosity of the gel.

Author Contributions: Supervision, S.R.-G., P.R., and F.H.; Writing-Original draft, K.G.U.

Funding: This research received no external funding.

Acknowledgments: The authors wish to acknowledge Teesside University for providing the materials and facilities to perform the experiments. They would also like to express their appreciation to the Petroleum Technology Development Fund (PTDF) in Nigeria for the funding of the project.

Conflicts of Interest: The authors declare no conflicts of interest.

\section{References}

1. Li, X.; Xu, Z.; Yin, H.; Feng, Y.; Quan, H. Comparative studies on enhanced oil recovery: Thermoviscosifying polymer versus polyacrylamide. Energy Fuels 2017, 31, 2479-2487. [CrossRef]

2. Nwidee, L.N.; Barifcani, A.; Maxim, L.; Sarmadivaleh, M.; Iglauer, S. A realistic look at nanostructured material as an innovative approach for enhanced oil recovery process upgrading. Recent insights in petroleum science and engineering. InTechOpen 2018, 155-188. [CrossRef] 
3. Sharma, T.; Suresh Kumar, G.; Sangwai, J.S. Enhanced oil recovery using oil-in-water $(o / w)$ emulsion stabilized by nanoparticle, surfactant and polymer in the presence of NaCl. Geosyst. Eng. 2014, 17, $195-205$. [CrossRef]

4. Al Anssari, S.; Arif, M.; Wang, S.; Barifcani, A.; Lebedev, M.; Iglauer, S. Wettability of nanofluid-modified oil-wet calcite at reservoir conditions. Fuel 2018, 211, 405-414. [CrossRef]

5. Sandiford, B. Laboratory and field studies of water floods using polymer solutions to increase oil recoveries. J. Petrol. Technol. 1964, 16, 917-922. [CrossRef]

6. Jennings, R.R.; Rogers, J.H.; West, T.J. Factors influencing mobility control by polymer solutions. J. Petrol. Technol. 1971, 23, 391-401. [CrossRef]

7. Mungan, N. Shear viscosities of ionic polyacrylamide solutions. Soc. Petrol. Eng. J. 1972, 12, 469-473. [CrossRef]

8. Martin, F.D.; Sherwood, N.S. The effect of hydrolysis of polyacrylamide on solution viscosity, polymer retention and flow resistance properties. SPE 5339. In Proceedings of the Rocky Mountain Regional Meeting of the Society of Petroleum Engineers of AIME, Denver, CO, USA, 7-9 April 1975.

9. Sorbie, K.S. Polymer-Improved Oil Recovery, 1st ed.; Blackie and Son Glasgow: Glasgow, Scotland, 1991.

10. Zhu, Y.; Lei, M.; Zhu, Z. Development and performance of salt-resistant polymers for chemical flooding. In Proceedings of the Middle East Oil and Gas Show and Conference, Manama, Bahrain, 8-11 March 2015; pp. 1-14.

11. Zhu, D.; Wei, L.; Wang, B.; Feng, Y. Aqueous hybrids of silica nanoparticles and hydrophobically associating hydrolysed Polyacrylamide used for EOR in high-temperature and high-salinity reservoirs. Energies 2013, 7, 3858-3871. [CrossRef]

12. Lockhart, T.P.; Burrafato, G. Water production control with relative permeability modifiers. In Proceedings of the 16th World Petroleum Congress (WPC-30134), Calgary, AB, Canada, 11-15 June 2000; pp. 196-197.

13. Sun, Y.; Saleh, L.; Bai, B. Measurement and impact factors of polymer rheology in porous media, Rheology, Dr. Juan De Vicente (Ed.). InTechOpen 2012, 187-202. [CrossRef]

14. Levitt, D.B.; Pope, G.A.; Jouenne, S. Chemical degradation of polyacrylamide polymers under alkaline conditions. SPE 129879. In Proceedings of the Improved Oil Recovery Symposium, Tulsa, OK, USA, 24-28 April 2011.

15. Moradi-Araghi, A.; Doe, P.H. Hydrolysis and precipitation of polyacrylamides in hard brines at elevated temperatures. SPE Reserv. Eng. 1987, 2, 189-198. [CrossRef]

16. Glover, P. Reservoir Fluids. 2012. Available online: http://homepages.see.leeds.ac.uk/ earpwjg/PG_EN/ CD\%20Contents (accessed on 10 February 2017).

17. Muller, G.; Fenyo, J.C.; Seleny, E. High molecular weight hydrolysed polyacrylamides. III. Effect of temperature on chemical stability. J. Appl. Polym. Sci. 1980, 25, 627-633. [CrossRef]

18. Zaitoun, A.; Potie, B. Limiting Conditions for the use of Hydrolysed Polyacrylamides in Brines Containing Divalent Ions. SPE 11785. In Proceedings of the International Symposium on Oilfield and Geothermal Chemistry, Denver, CO, USA, 1-3 June 1983; pp. 143-150.

19. Ryles, R.G. Chemical stability limits of water-soluble polymers used in oil recovery processes. SPE Reserv. Eng. 1988, 3, 23-34. [CrossRef]

20. Albonico, P.; Lockhart, T.P. Divalent ion-resistant polymer gels for high-temperature applications: Syneresis-inhibiting additives. SPE-25220. In Proceedings of the SPE International Symposium on Oilfield Chemistry, New Orleans, LA, USA, 2-5 March 1993.

21. Seright, R.S.; Campbell, A.R.; Mozley, P.S.; Han, P. Stability of partially hydrolysed polyacrylamides at elevated temperatures in the absence of divalent cations. SPE 121460. In Proceedings of the SPE International Symposium on Oilfield Chemistry, Houston, TX, USA, 18-21 April 2010; Volume 15, pp. 341-348.

22. Uranta, K.G.; Gomari, S.R.; Russel, P.A.; Hamad, F. Determining safe maximum temperature point (SMTP) for Polyacrylamide polymer (PAM) in saline solutions. J. Oil Gas Petrochem. Sci. 2018, 1, 26-33. [CrossRef]

23. Knight, B.L. Reservoir stability of polymer solutions. J. Petrol. Technol. 1973, 25, 618-626. [CrossRef]

24. Lewandowska, K. Comparative studies of rheological properties of polyacrylamide and partially hydrolyzed polyacrylamide solutions. J. Appl. Polym. Sci. 2007, 103, 2235-2241. [CrossRef]

25. Borling, D.; Chan, K.; Hughes, T.; Sydansk, R. Pushing out the Oil with conformance control. Oilfield Rev. 1994, 6, 44-58. 
26. Akbari, S.; Mahmood, S.M.; Tan, I.M.; Hosein, G.; Ling, O.L. Assessment of polyacrylamide based Co-Polymers enhanced by functional group modifications with regards to salinity and hardness. Polymers 2017, 9, 647. [CrossRef]

27. Stuart, B.H. Modern Infrared Spectroscopy, 2nd ed.; John Wiley \& Sons: Chichester, UK, 1996; pp. 81-83.

28. Kavanagh, G.M.; Ross-Murphy, S.B. Rheological characterisation of polymer gels. Prog. Polym. Sci. 1998, 23, 533-562. [CrossRef]

29. Meyer, B., Jr. Polymer Science Textbook, 1st ed.; John Wiley \& Sons: New York, NY, USA, 1971; pp. $185-191$.

30. Thomas, A.; Gaillard, N.; Favero, C. Some key features to consider when studying acrylamide-based polymers for chemical enhanced oil recovery. Oil Gas Sci. Technol.-Rev. IFP Energies Nouv. 2012, 67, 887-902. [CrossRef]

(c)

(C) 2018 by the authors. Licensee MDPI, Basel, Switzerland. This article is an open access article distributed under the terms and conditions of the Creative Commons Attribution (CC BY) license (http:/ / creativecommons.org/licenses/by/4.0/). 